\title{
19. The data epic: Visualization practices for narrating life and death at a distance
}

\author{
Jonathan Gray
}

\begin{abstract}
This chapter proposes the notion of the 'data epic', which is examined through two works of 'cinematic data visualization': The Fallen of World War II and The Shadow Peace: The Nuclear Threat. These pieces mobilize an aesthetics of distance to narrate life and death at scale, in past and possible global conflicts. While previous studies of quantification emphasize the function of distance in relation to aspirations of objectivity, this chapter explores other narrative and affective capacities of distance in the context of 'public data culture'. The data epic can thus enrich understanding of how data are rendered meaningful for various publics, as well as the entanglement of data aesthetics and data politics involved in visualization practices for picturing collective life.
\end{abstract}

Keywords: Data politics; Data aesthetics; Data practices; Sociology of quantification; Distance; Scale

\section{Introduction}

'In Visual Education we should think of the onlooker's emotional habits, but that does not imply that we have to make charts and their captions emotional. People like to get an opportunity to judge for themselves and to reach their decisions without feeling themselves bullied by "visual dictators" who take care of the public's "visual food". (Neurath, 1944, p. 65)

'In my work, I try to find ways to make statistical information less boring and intimidating. I believe it's often appropriate to express numbers with emotion and cinematic drama, particularly when there is a humanitarian

Engebretsen, M. and H. Kennedy (eds.), Data Visualization in Society. Amsterdam: Amsterdam University Press, 2020 DOI 10.5117/9789463722902_CH19 
component. I'm hoping that new forms of data-driven storytelling can help us as an informed democracy close the troubling gap between expert and public opinion'. (Halloran, cited in Dvorsky, 2017)

'[...] it's important to slow down and take in the data part by part. That required a lot of shifting of gears these days, because my screen was a veritable anthology of narratives, and in many different genres. I had to shift between haiku and epics, personal essays and mathematical equations, Bildungsroman and Götterdämmerung, statistics and gossip [...]. The temporalities in these genres ranged from the nanoseconds of high-frequency trading to the geological epochs of sea level rise, chopped into intervals of seconds, hours, days, weeks, months, quarters, and years. [...] The economic sublime!' (Robinson, 2017)

How do data visualizations enable different ways of making sense of life and death 'at a distance'? How can they articulate not just 'ways of knowing' but also 'ways of feeling' with data? This chapter examines two projects by software developer, data analyst, and filmmaker Neil Halloran: The Fallen of World War II (2015) on deaths during the war; and The Shadow Peace: The Nuclear Threat (2017) on nuclear weapons, nuclear war scenarios, and peacekeeping efforts (both projects are available online at: http://www. fallen.io/). These have been variously described by their creator as 'cinematic data visualization', 'interactive documentary' and 'animated data-driven documentary about war and peace' (Halloran, 2015, 2017; and see http:// www.neilhalloran.com/).

The pieces are said to exemplify a novel way of doing data visualization. Regarding the first, writer and researcher Steven Pinker asks, 'Who would have thought that bar graphs (admittedly, with the help of haunting music) could overflow with human pathos?'. He goes on to comment that 'data graphics has become a major new medium of intellectual exposition and artistic expression' and that the 'war death data' are 'stunning' and 'emotionally ravaging' (Pinker, 2015). Both pieces were also critically acclaimed amongst practitioner communities, including winning prizes in the 'Information is Beautiful' data visualization awards for the 'Motion Infographic' (2015) and 'Humanitarian' (2017) categories. They were both crowdfunded and freely distributed online, with the former piece winning a 'Best of 2015' award from video-sharing platform Vimeo.

Both of these works by Halloran use data visualizations to narrate war deaths and the potential effects of nuclear weapons at the level of populations, over periods of decades and centuries. As such, a defining feature of 
both is mobilizing data to tell stories 'at a distance' and to comprehend the societal consequences of war and nuclear weapons across space and time, beyond the level of individual incidents. These works explore the narrative and affective capacities of distance, in a way which can be distinguished from (but which may also serve to reinforce and potentially reify) its role as a methodological ideal in the production of knowledge and objectivity. The data epic can thus enrich understanding of how data are rendered meaningful for various publics, as well as how data aesthetics and data politics are entangled in visualization practices for picturing collective life.

\section{Public data cultures and aesthetics of distance}

Practices of quantification and datafication are often used to understand and narrate phenomena at scale in order to identify and articulate patterns, trends, and dynamics across different cases and settings. As Porter puts it, 'quantification is a technology of distance', which aims to support objectivity by attempting to produce knowledge independent of the particular people who make it' (1996, p. ix). A similar argument is made by Daston and Galison, who argue that 'emotional distance' was considered a condition of objectivity, citing nineteenth-century statistician Karl Pearson's call for citizens to set aside their 'own feelings and emotions' in order to be impartial and impersonal (2010, pp. 29, 380, 196). Social and historical studies of quantification have explored how numbers can be put to work in the service of institutions of objectivity in science, management, and governance (see e.g. Porter, 1986, 1996; Desrosières, 2002; Rottenburg, Merry, Park, \& Mugler, 2015).

Such data practices have significance outside of these institutional settings, including as part of what I propose to call 'public data cultures' through which various publics are invited to participate in making sense with data. For example, the work of Marie and Otto Neurath and the 'visual education' activities of their Isotype Institute sought to create a common pictorial language of 'isotypes' - pictorial representations of data-used in public exhibitions, pamphlets, and other materials about a wide range of issues and areas of life such as demography, economics, work, health, agriculture, industry, and politics (Neurath \& Kinross, 2009). They thus aimed to use data not just to advance science or management, but also in the service of advocacy, journalism, and democratic participation (Rayward, 2017). The subtraction of emotion, decoration, and detail in such projects can be understood in relation to modernist ideals of an 'unaesthetic aesthetics' (Galison, 1990). 
The use of data to produce distant perspectives is not limited to impartial, 'facty' aesthetics. As Kennedy and Hill note, data visualizations can have 'emotional and affective, not just cognitive and rational' capacities (2017, p. 10). Halloran's work explores the aesthetic and affective dimensions of the distance that data performs. Heterogeneous data about population, mortality, war, and peace are assembled, visualized, animated, and sequenced in the context of animated graphics and interactive features in order to tell stories about the fate of human creatures at sweeping scales across time and space. These 'thin descriptions', as Porter calls them (2012), are mobilized to facilitate different kinds of experiences and ways of making sense of collective life at a distance.

Such aesthetics of distance may be understood in relation to recent work on the 'data sublime' (Liu, 2004; Davies, 2015; Stallabrass, 2007). The data sublime is said to arise from Stallabrass's contention that 'the impression and spectacle of a chaotically complex and immensely large configuration of data' can play a role similar to 'mountain scenes and stormy seas' for nineteenth-century viewers (2007, p. 82.). As Davies suggests in relation to big data technologies, we may find an aesthetic of awe which 'functions beyond empiricism' through a 'sheer quantitative magnitude' which is 'as disturbing as exciting' (2015). These notions of the data sublime draw on traditions of thinking about the aesthetics of the sublime that rose to prominence in the eighteenth century - such as Burke's notion that the sublime produces 'the strongest emotion which the mind is capable of feeling' associated with a 'great extreme of dimension' (1998, pp. 36, 66). Kant says that the sublime is the 'absolutely great' and shifts emphasis from 'objects of the sense' - which can elicit but never embody such greatness - to a 'faculty of mind transcending every standard of the senses' (2007, pp. 78, 81). This includes what he calls the 'mathematically sublime', which is not simply 'greatness of number' but 'the fact that in our onward advance we always arrive at proportionately greater units' (p. 87).

Halloran's work can be viewed as an emerging style of data practice which I characterize as the 'data epic'. The projects have moments of tilting towards a data sublime, as well as other aesthetic and affective dimensions which I shall explore in the following sections. They affirm the affective and narrative capacities of data visualizations, which operate in combination with other images, film, music, audio effects, textual annotations, overlays, and voice-over. The two pieces can be compared with other forms of 'conventionalized representations' (Becker, 2007) about war, demography, and mortality - from documentary film and war memorials, to isotypes and mythological constellations - as well as giving rise to their own conventions and techniques for making sense with data visualization that are shared 
across the two projects. The data epic may be viewed as an emerging area for research and practice, contributing to recent work on the emotional capacities of data (Kennedy \& Hill, 2017).

\section{The Fallen of World War II}

The Fallen of World War II is an 18-minute, interactive documentary about the 'human cost of the second World War'. Rather than focusing on 'individual war stories', its main characters are isotype-style representations of 'tens of millions of people whose lives were cut short by the war' (Halloran, 2015). While the repeated pictorial figures strongly resemble the visual style of the Isotype Institute, they are mobilized in a way which departs from the latter's unadorned and unemotional aspirations.

The setting for the piece starts with a blackboard, and transitions to an abstracted endless canvas whereby historical events are re-staged with data. Blackboard figures sketched onto a virtual blackboard are transformed into polished, computer-generated markers and timelines. The limits of the screen are used as a device to emphasize scale, such that timelines and graphs spill beyond its limits, and the screen pans or zooms out in order to account for the large numbers of deaths. A soundtrack of bass tones and reverb effects contributes to an atmosphere of endless space and timelessness.

The narrative starts with a chalk line for the 'average lifespan', the statistical equivalent of 'everyman' or the ordinary person. This is used as a device to transition from an individual perspective to the collective scale of 'lives cut short', such that numerous white lines enter from the left of the screen and terminate in a red block representing WWII (Figure 19.1).

While emphasizing the scale of death, The Fallen also uses visual strategies to connect visual representations of large numbers with individual lives. For example, we are shown a mass of white silhouettes with more individual details and features pouring out of a single isotype figure (Figure 19.2). This is accompanied by a rushing sound like a rainstick that suggests a sound for each individual as well as for the collective. This collective is then subsumed back into the isotype.

These isotype figures are then stacked up into charts to represent the scale of war deaths by nationality, by region of conflict, and by battle. Again, sound design plays a crucial role in the experience of distance and scale: a click is added for each figure, until the click becomes a whir. To convey the vast numbers of Soviet deaths, the screen slowly pans up a red column and the music fades out until there is nothing but a single note, the sound of high winds 


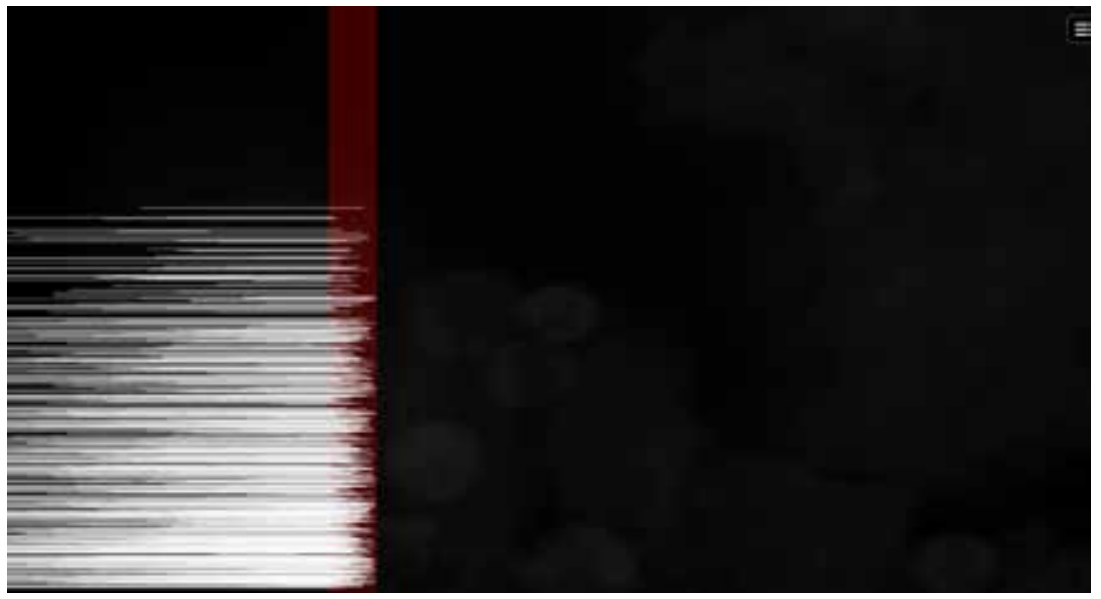

Figure 19.1. The white timelines of individual lives ending in the red block of WWII. From The Fallen of WWII. Retrieved from http://www.fallen.io/ww2/. Copyright 2015 by N. Halloran. Reprinted with permission.

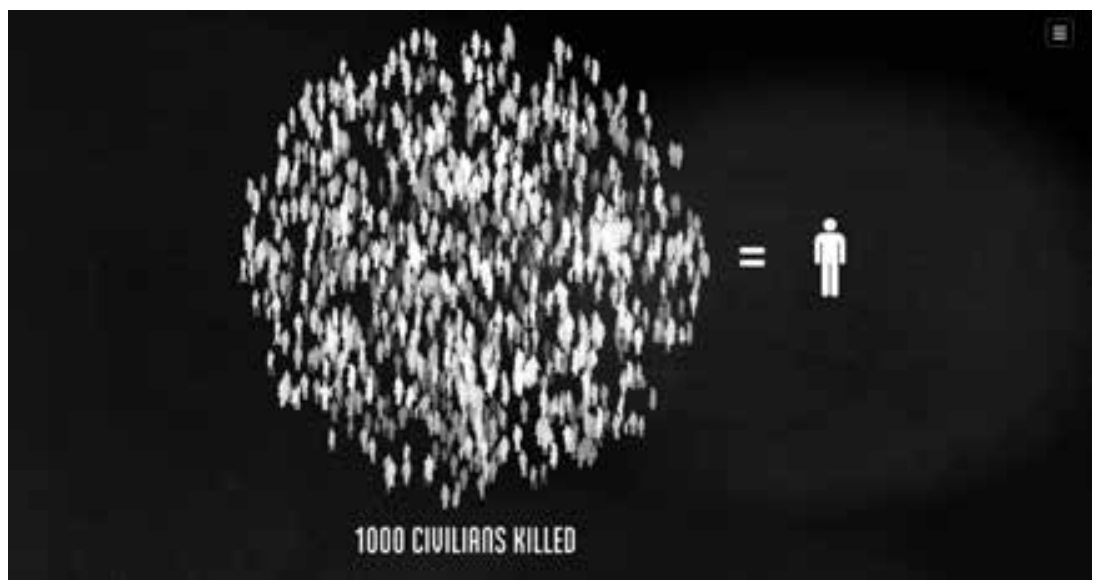

Figure 19.2. Group of silhouettes rendered equivalent to an isotype figure. From The Fallen of WWII. Retrieved from http://www.fallen.io/ww2/. Copyright 2015 by N. Halloran. Reprinted with permission.

and the whirring sound of the isotypes being added (Figure 19.3). Eventually the count stops and the figure of '8.7 million' appears. A similar approach is taken with people killed in the Holocaust: the screen zooms out from a huge block of isotypes representing millions of people killed during the Holocaust, with sound effects contributing to a sense of the vastness of the scene.

Other techniques are used to allude to individual lives within the vast multitudes of deaths. This includes combining charts with depictions of scenes at a human scale. Military drums accompany the transition from 


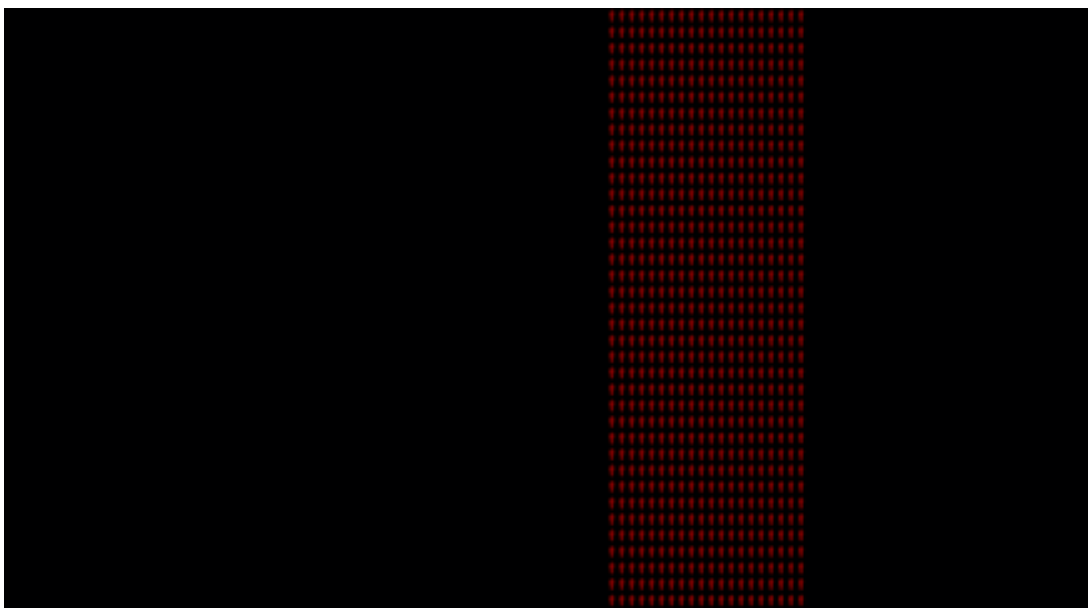

Figure 19.3. Panning up a long column of Soviet deaths. From The Fallen of WWII. Retrieved from http://www.fallen.io/ww2/. Copyright 2015 by N. Halloran. Reprinted with permission.

isotypes to photographs of battles. A photograph showing a soldier about to shoot a woman and child transitions into a silhouette outline, which is then shown as one amongst many outlines contained within a single isotype, which itself is one amongst many isotypes representing deaths in concentration camps. These techniques are not intended to undo or negate the distance which is articulated through the visualizations, but rather to modify how they are meaningful by connecting vast scenes to recognizable and relatable ones. It is precisely by alternating between scales that such an epic narrative of life and death at a distance is enabled.

After exploring deaths across the world, the piece zooms out to show 70 million deaths for the war, depending on 'who is counting and what civilian deaths get included'. The total estimated deaths in WWII are then compared with a chart showing deaths in other wars and atrocities. The empty space above the bars in the chart is filled with light bars that extend beyond the screen, as the narrator comments: 'peace is a difficult thing to measure: it is a bit like counting the people who didn't die and wars that never happened'. The quantification of death is thus contrasted with the difficulty of quantifying peace, to which viewers are nevertheless encouraged to attend.

\section{The Shadow Peace: The Nuclear Threat}

The theme of accounting for peace is taken up in a sequel, The Shadow Peace: The Nuclear Threat, which examines scenarios of nuclear war and 


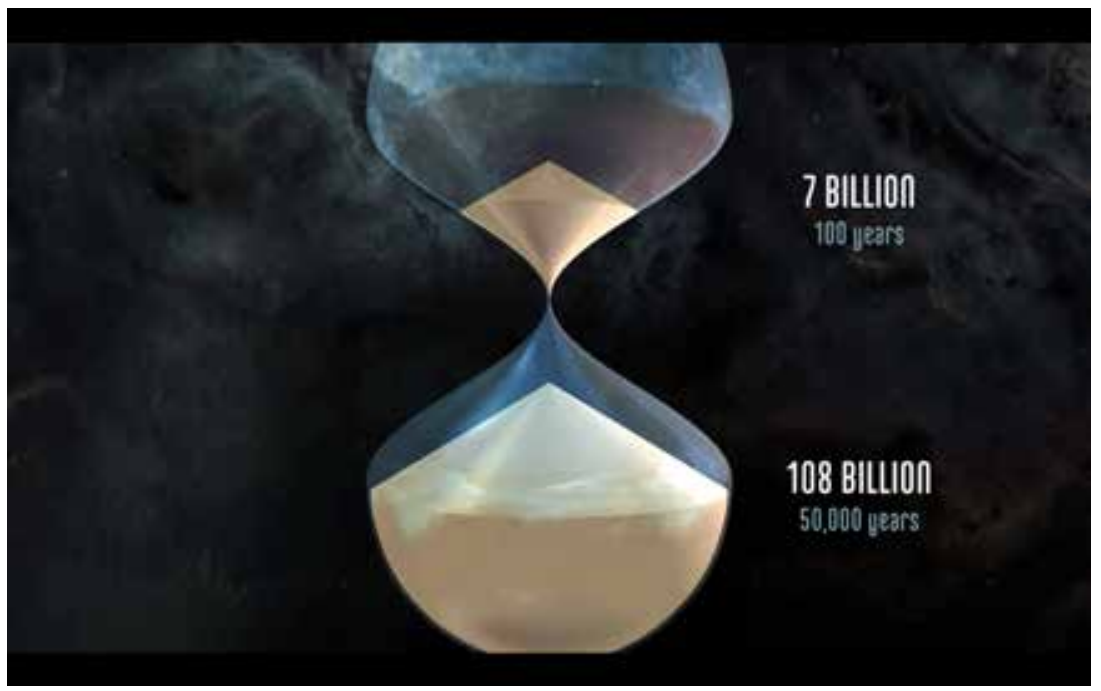

Figure 19.4. Comparing population of total living with total dead. From The Shadow of Peace: The Nuclear Threat. Retrieved from http://www.fallen.io/shadow-peace/1/. Copyright 2017 by N. Halloran. Reprinted with permission.

peacekeeping efforts to avoid it. The setting for this piece is also a vast and apparently limitless canvas. Just as The Fallen begins with the demographic average, so The Shadow Peace commences with a visualization of demographic entities: falling cubes representing 4.6 people born into the world every second, each with its own accompanying sound. The narrative shifts from this fathomable number to the aggregation of '140 million births a year', accompanied by deep synth and reverb sounds suggestive of a large space. The screen pans out to show falling cubes as a barely visible trickle onto an enormous pyramid representing the entire living population. Another trickle comes down from the living towards another pyramid of the dead. The two pyramids are depicted as part of a vast hourglass, against a background of what appears to be clouds or distant nebulae (Figure 19.4). Thus data visualizations are mobilized to show us the entirety of human life and death at a distance in the form of a cosmic symbol representing the passage from life to death. This cosmic setting is later reinforced with constellations of stars which transform into weapons and graphs.

Just as isotypes represent a thousand people in The Fallen, pyramids are broken down into blocks representing one million people in The Shadow Peace, before being rearranged onto a timeline showing the rise and fall of earth's population over time. The scale of deaths is illustrated through a combination of isotype charts, photographs, and annotated maps narrating events such as nuclear strikes on Japan during WWII. 


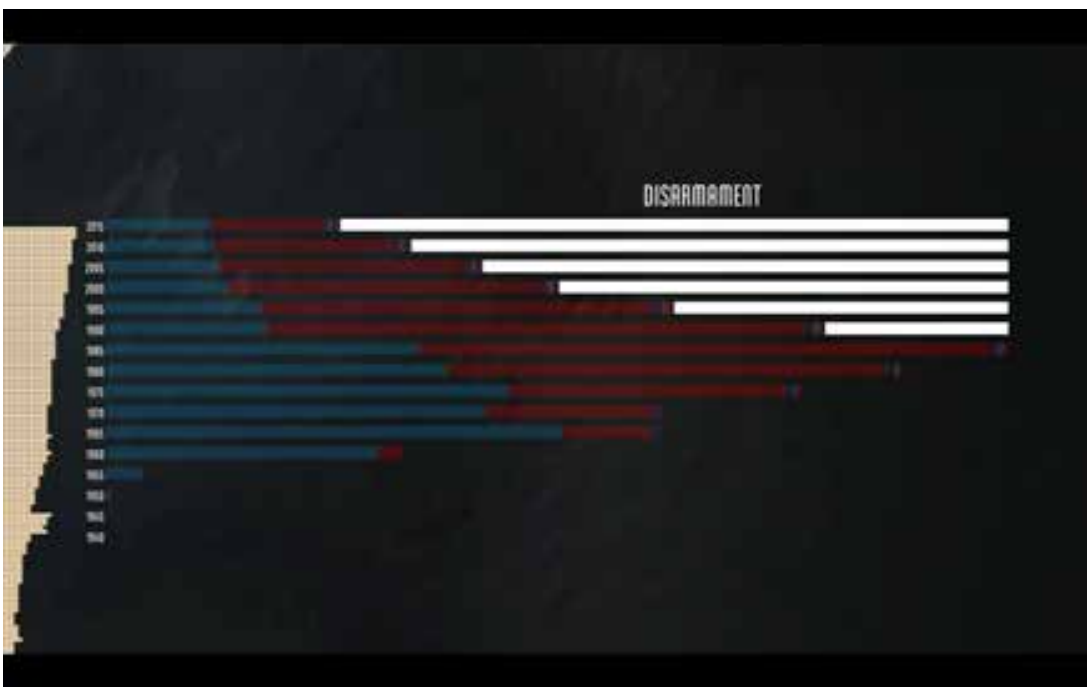

Figure 19.5. Visualizing nuclear disarmament alongside proliferation. From The Shadow of Peace: The Nuclear Threat. Retrieved from http://www.fallen.io/shadow-peace/1/. Copyright 2017 by N. Halloran. Reprinted with permission.

To examine the possible catastrophic consequences of nuclear war, a scenario of ' 2,000 strikes' shows a map of the earth with red dots indicating nuclear strikes appearing rapidly across the US along with the names of cities-'New York', 'Cleveland', 'Yonkers' - appearing and fading from view, before panning to show strikes in Western Europe, Eastern Europe, and Asia. A timeline showing deaths per decade depicts the effects of this nuclear war scenario as equivalent to 'almost ten World War IIs in three weeks', accompanied by discussions of nuclear winter and nuclear famine.

The focus then shifts to nuclear weapons-showing peaks in the mid1980 s, and the effects of disarmament highlighted by white bars showing the negative space above bars representing numbers of weapons (Figure 19.5), echoing the visual approach to highlighting peace in The Fallen. The narrative then turns to the proliferation and non-proliferation of nuclear weapons, different approaches to prevent nuclear war, accompanied by outlines of weapons presented as constellations of stars under the heading 'instruments of war' and a list of prevention strategies under 'instruments of peace'. The piece concludes with a discussion of 'what works in preventing war', reviewing the activities and effects of UN Peacekeepers, and contrasting belief in the technologies underpinning nuclear weapons with scepticism about 'statistics and the science of less tangible things, such as peace'. 


\section{Aesthetics and politics of the data epic}

The Fallen and The Shadow Peace use similar aesthetic approaches for using data visualizations to make sense of life and death at a distance. They both have moments of the 'data sublime', such as the portrayal of historical events in settings of limitless space; the use of music and sound effects to indicate vast numbers of lives and deaths; the use of panning, zooming, and animated effects to dramatize the revelation of large numbers; and the use of thematic motifs alluding to visual cultures of death, spirituality, and the cosmos, such as war memorials and mythological constellations (Table 19.1).

\section{Table 19.1 Comparison of features contributing to aesthetics of data sublime in Halloran 2015 and 2018}

\begin{tabular}{|c|c|c|}
\hline & The Fallen of World War II & $\begin{array}{l}\text { The Shadow Peace: The Nuclear } \\
\text { Threat }\end{array}$ \\
\hline Implied setting & Endless canvas. & - Space. \\
\hline Sound & $\begin{array}{l}\text { - } \quad \text { Lack of voice-over contributes } \\
\text { to dramatization of key } \\
\text { scenes; } \\
\text { - } \quad \begin{array}{l}\text { Sound effects imply vast } \\
\text { space; }\end{array} \\
\text { - Sonification to accompany } \\
\text { data visualizations - from } \\
\text { individual clicks to whirring to } \\
\text { indicate scale; } \\
\text { - Wind noises emphasize } \\
\text { height of graphs; } \\
\text { - Emotional piano music. }\end{array}$ & $\begin{array}{l}\text { - } \quad \text { Lack of voice-over contributes } \\
\text { to dramatization of key scenes; } \\
\text { - } \quad \text { Sound effects imply vast space; } \\
\text { - } \quad \text { Sonification to accompany } \\
\text { data visualizations - from } \\
\text { individual clicks to whirring to } \\
\text { indicate scale; } \\
\text { - } \quad \text { Submarine-like sounds and } \\
\text { deep synths give sense of space; } \\
\text { - } \quad \text { Melancholy music for strike } \\
\text { scenes. }\end{array}$ \\
\hline $\begin{array}{l}\text { Panning and } \\
\text { zooming effects }\end{array}$ & $\begin{array}{l}\text { - Slow upward pan to show } \\
\text { scale of Russian military } \\
\text { deaths. }\end{array}$ & $\begin{array}{l}\text { - Slow downward pan and out- } \\
\text { ward zoom to show pyramid } \\
\text { representing populations; } \\
\text { - Slow pans across globe to } \\
\text { show projected nuclear strikes. }\end{array}$ \\
\hline Thematic motifs & $\begin{array}{l}\text { Equidistant layout of many } \\
\text { figures alludes to war memo- } \\
\text { rial practices used to indicate } \\
\text { scale (e.g. in scenes with US } \\
\text { soldiers accompanied by } \\
\text { falling flag, figures represent- } \\
\text { ing deaths in Holocaust, and } \\
\text { in image used for video still). }\end{array}$ & $\begin{array}{l}\text { - Cosmic-scale hourglass } \\
\text { representing total living and } \\
\text { dead populations; } \\
\text { - } \quad \text { Earth from space; } \\
\text { - Constellations to show } \\
\text { weapons and charts, invoking } \\
\text { mythological sense of the } \\
\text { eternal. }\end{array}$ \\
\hline
\end{tabular}

In addition to these aspects of the data sublime, other strategies are used not just to produce an aesthetic of distance but also to connect these vast 
scales to the lives and deaths of individuals. This includes the use of graph features (such as segmentation, annotation, and visual cues); the use of photographs and other media to highlight individual people and events; zooming and panning effects; and the use of sonic textures to provide a sense of individuals within collectives, such as clicks to represent individual deaths (Table 19.2).

Table 19.2 Comparison of features contributing to connection between scale and individual in Halloran 2015 and 2018

\begin{tabular}{|c|c|c|}
\hline & The Fallen of World War II & $\begin{array}{l}\text { The Shadow Peace: The Nuclear } \\
\text { Threat }\end{array}$ \\
\hline Graphs features & 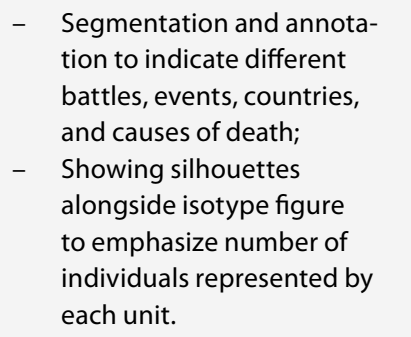 & $\begin{array}{l}\text { - Segmentation and annotation } \\
\text { to indicate different events, } \\
\text { countries, and causes of death; } \\
\text { - } \quad \text { Showing trickle of blocks } \\
\text { depicting birth and death } \\
\text { rates to emphasize individuals } \\
\text { within population pyramids. }\end{array}$ \\
\hline Media formats & $\begin{array}{l}\text { - Transitions into photographs } \\
\text { to highlight individual } \\
\text { people, battles. }\end{array}$ & $\begin{array}{l}\text { - Transitions into photographs } \\
\text { and video clips to highlight } \\
\text { individual people and events. }\end{array}$ \\
\hline $\begin{array}{l}\text { Panning and } \\
\text { zooming effects }\end{array}$ & $\begin{array}{l}\text { - Zooming into timeline } \\
\text { and highlighting groups } \\
\text { of isotypes in order to } \\
\text { emphasize individual events. }\end{array}$ & $\begin{array}{l}\text { - Slow pan across globe } \\
\text { showing nuclear strikes, with } \\
\text { points being gradually added } \\
\text { to emphasize each incident. }\end{array}$ \\
\hline Sound & 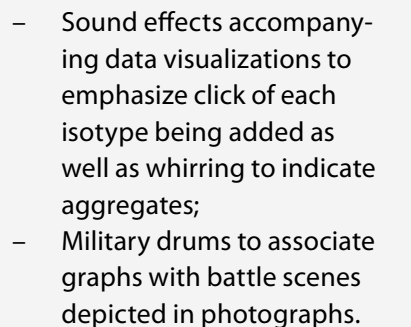 & $\begin{array}{l}\text { - Sound effects accompany- } \\
\text { ing data visualizations to } \\
\text { emphasize tone of each birth, } \\
\text { death, and nuclear strike as } \\
\text { well as whirring to indicate } \\
\text { aggregates. }\end{array}$ \\
\hline
\end{tabular}

Such strategies serve both to highlight people and situations at a more familiar and relatable scale, perhaps to counter what Boltanski calls the 'massification' of suffering associated with a politics of pity as opposed to a politics of justice (1999, p. 13). At the same time, we are shown the relationship between individual actors and scenes on the one hand, and aggregates, trends, and patterns at a larger scale on the other, such that the former are enlisted to rhetorically support and validate the graphs, charts, 
timelines, and other data visualizations. Halloran characterizes this in terms of the addition of 'weight':

Bar charts are great for showing relative scale, but they can feel disconnected from what it is they represent. By building the bars out of stacks of figures, each representing 1,00o people who died, I tried to make the bars feel bigger and weightier. (Neil Halloran, creator of Fallen.io, cited in Emory, 2015)

His visual techniques to traverse from the aggregated numbers of the graph (portraying death at a distance, sometimes inflected with a sense of the sublime) to the granularity and comparative intimacy of photographs and video clips can be read in the context of what Latour calls the 'zoom effect' (2014, p. 121), fabricating a smooth trajectory between different and discontinuous knowledge-making and cultural practices. Numbers and statistics about war deaths may be seen as 'thin descriptions' (Porter, 2012), subtracting detail, decontextualizing people and events, articulating and attending to only certain aspects of situations through social practices of commensuration (making comparable through common metrics) and quantification (making numbers) which thereby enable styles of reasoning and sense-making across situations, space, and time (Espeland \& Stevens, 1998, 2008; Verran, 2010, 2015). Halloran's strategies to recontextualize and thicken data by visually associating graphical aggregates to images of individuals could be read as a form of what Desrosières calls 'proof in use realism', whereby data are treated as 'self-sufficient' and 'without footnotes to interfere with the message' (2001, p. 346). While Halloran intersperses his narrative with verbal caveats about controversies of estimation, quantification, probability, and inference, the data visualization practices of the two pieces stabilize and solidify numbers, and portray them as 'given', at least provisionally, for the purposes of narrating past and future events from afar, including through the anchoring of averages, estimates, and provisional counts with audiovisual 'weight' and zoom effects.

Such visual practices may thus risk implying a misleading sense of immediacy, foregrounding the direct representational capacities of numbers in a way which leads attention away from social, cultural, and political processes involved in their making-including practices of counting, classifying, estimating, averaging, contesting, and publishing them. Even operations as apparently straightforward as counting can be contentious and dependent on fragile networks, infrastructures, and practices, such as determining group membership, interpreting scientific images, or estimating 
crowd sizes (Martin \& Lynch, 2009). The settings of the infinite canvas and the cosmic surround may be taken as a rhetorical embodiment of what Haraway calls 'disembodied vision' and the 'god trick of seeing everything from nowhere' which she associates with the visualizing technologies of science, management, and the military (1988, pp. 581, 590). As Lauren Klein recently puts it, 'the view from a distance, is, of course, as much of a view from a particular place as a view from up close' (2018).

How might we surface the particular situated perspectives that underpin these data epics? As well as looking at the design process, one might also examine the making, selection, and translation of data which shape how life and death are rendered intelligible and experienceable through data visualizations (Gray, Bounegru, Milan, \& Ciuccarelli, 2016; Gray, 2018). Both pieces involve gathering and animating different types of numbers from different information sources and data infrastructures (Gray, Gerlitz, \& Bounegru, 2018), which are listed in a 'data sources' section, including both original and processed datasets. A Google Fusion table file linked to The Fallen gives a list of 602 sources, most of which are from Wikipedia (81 percent), with the remaining 19 percent from a combination of academic, military, governmental, and hobbyist websites. These sources have been transformed through a combination of normalizing, adjusting, averaging, and interpolating in order to render numbers commensurable and visualizable. As well as the work to integrate and harmonize different sources of information, the apparent continuity between them is further enabled through the use of common visual formats, styles, sounds, colour, motifs (such as isotypes), and other effects. These provide an aesthetic vocabulary for dramatizing quantified collectives in narratives at an epic scale.

The data epic may thus be considered as another emerging area of practice wherein one might study how 'ideology, power and politics are at work in data visualisation' (Kennedy, Hill, Aiello, \& Allen, 2016, p. 732), including in relation to the making of public data, and the particular ways in which data are made public. The broad narratives of war, peace, stability, and violence which are performed through data are not without baggage. War deaths are considered in terms of battles between nation states, rather than the colonial projects in which they were involved. Viewers are invited into particular subject positions in witnessing these narratives. The question of who has agency and who can do what to whom in situations of life and death, peace and war, may be considered in terms of what Mbembe calls the 'necropolitical', or 'contemporary forms of subjugation of life to the power of death' (2003, p. 39). Halloran cites Steven Pinker's argument about the decline of violence after WWII as the inspiration for the end of The 
Fallen. But the selection and interpretation of events in order to make this argument are not uncontested, with some suggesting that 'war and violence are not declining, but they are being transformed', in particular through the replacement of interstate conflict with violence in poorer countries armed and supported by richer ones (Mann, 2018, p. 37).

The techniques and politics of producing aesthetics of distance exemplified in Halloran's data epics - oscillating between vast, sublime perspectives across space and time and the texture of particular situations at a relatable scale-are an emerging area of public data culture for both researchers and practitioners to attend to. They may be relevant in relation to narrating and making sense of other complex and transnational issues such as climate change, migration, and inequality, where it may be desirable to attend to dynamics of injustice with different registers, scales, and temporalities, as well as scrutinizing the means through which such perspectives are produced.

\section{References}

Becker, H. S. (2007). Telling about society. Chicago: University of Chicago Press.

Boltanski, L. (1999). Distant suffering: Morality, media and politics. Cambridge \& New York: Cambridge University Press.

Burke, E. (1998 [1757]). A philosophical enquiry into the origin of our ideas of the sublime and beautiful. Oxford: Oxford University Press.

Daston, L., \& Galison, P. (2010). Objectivity. New York: Zone Books.

Davies, W. (2015, January 12). The Data Sublime. The New Inquiry. Retrieved from https://thenewinquiry.com/the-data-sublime/

Desrosières, A. (2001). How real are statistics? Four possible attitudes. Social Research, 68(2), 339-355.

Desrosières, A. (2002). The politics oflarge numbers: A history of statistical reasoning (C. Naish, Trans.). Cambridge, MA: Harvard University Press.

Dvorsky, G. (2017, November 8). Disturbing data visualization shows just how many people would die in a nuclear war. Gizmodo. Retrieved from https://gizmodo. com/disturbing-data-visualization-shows-just-how-many-peopl-1797748588

Emory, S. (2015, June 28). Data visualizing WWII's devastating death toll. VICE. Retrieved from https://creators.vice.com/en_uk/article/4xqq73/ inside-look-data-visualizing-wwiis-death-toll

Espeland, W. N., \& Stevens, M. L. (1998). Commensuration as a social process. Annual Review of Sociology, 24(1), 313-343. https://doi.org/10.1146/annurev.soc.24.1.313 
Espeland, W. N., \& Stevens, M. L. (2008). A sociology of quantification. European Journal of Sociology / Archives Européennes de Sociologie, 49(3), 401-436. https:// doi.org/10.1017/Soo03975609000150

Galison, P. (1990). Aufbau/Bauhaus: Logical positivism and architectural modernism. Critical Inquiry, 16(4), 709-752.

Gray, J. (2018). Three aspects of data worlds. Krisis: Journal for Contemporary Philosophy, 1.

Gray, J., Bounegru, L., Milan, S., \& Ciuccarelli, P. (2016). Ways of seeing data: Toward a critical literacy for data visualizations as research objects and research devices. In: S. Kubitschko \& A. Kaun (Eds.), Innovative methods in media and communication research. (pp. 227-251). Cham: Palgrave Macmillan.

Gray, J., Gerlitz, C., \& Bounegru, L. (2018). Data infrastructure literacy. Big Data \& Society, 5(2), 1-13. https://doi.org/10.1177/2053951718786316

Halloran, N. (2015). The Fallen of WWII [Video file]. Retrieved May 1, 2018 from http://www.fallen.io/ww2/

Halloran, N. (2017). The Shadow Peace: The Nuclear Threat [Video file]. Retrieved May 1, 2018 from http://www.fallen.io/shadow-peace/1/

Haraway, D. (1988). Situated knowledges: The science question in feminism and the privilege of partial perspective. Feminist Studies, 14(3), 575-599. https://doi. org/10.2307/3178066

Kant, I. (2007). Critique ofjudgement (J. C. Meredith \& N. Walker, Trans.). Oxford: Oxford University Press.

Kennedy, H., Hill, R. L., Aiello, G., \& Allen, W. (2016). The work that visualisation conventions do. Information, Communication and Society, 19(6), 715-735. https:// doi.org/10.1080/1369118X.2016.1153126

Kennedy, H., \& Hill, R. L. (2017). The feeling of numbers: Emotions in everyday engagements with data and their visualisation. Sociology, 52(4), 830-848. https:// doi.org/10.1177/0038038516674675

Klein, L. (2018). Distant reading after Moretti. Paper presented at the MLA2018, New York. Retrieved from http://lklein.com/2018/o1/distant-reading-after-moretti/ Latour, B. (2014). Anti-Zoom. In S. Pagé, L. Bossé, H. U. Obrist, \& C. Staebler (Eds.), Olafur Eliasson: Contact. Paris: Flammarion. Retrieved May 1, 2018 from http:// www.bruno-latour.fr/node/6og Liu, A. (2004). Transcendental data: Toward a cultural history and aesthetics of the new encoded discourse. Critical Inquiry, $31(1), 49-84$.

Mann, M. (2018). Have wars and violence declined? Theory and Society, 47(1), 37-60.

Martin, A., \& Lynch, M. (2009). Counting things and people: The practices and politics of counting. Social Problems, 56(2), 243-266. https://doi.org/10.1525/ sp.2009.56.2.243 
Mbembe, A. (2003). Necropolitics. Public Culture, 15(1), 11-40. https://doi. org/10.1215/08992363-15-1-11

Neurath, O. (1944). The human approach to visual education. Health Education Journal, 2(2), 61-66. https://doi.org/10.1177/001789694400200204

Neurath, M., \& Kinross, R. (2009). The transformer: Principles of making isotype charts. London: Hyphen Press.

Pinker, S. (2015, August 23). On my radar: Steven Pinker's cultural highlights. The Guardian. Retrieved from https://www.theguardian.com/culture/2015/aug/23/ on-my-radar-steven-pinker-psychologist-author

Porter, T. M. (1986). The rise of statistical thinking, 1820-19oo. Princeton, NJ: Princeton University Press.

Porter, T. M. (1996). Trust in numbers: The pursuit of objectivity in science and public life. Princeton, NJ: Princeton University Press.

Rayward, W. B. (Ed.). (2017). European modernism and the information society: Informing the present, understanding the past. London: Routledge.

Robinson, K. S. (2017). New York 2140. New York: Orbit.

Rottenburg, R., Merry, S. E., Park, S.-J., \& Mugler, J. (Eds.). (2015). The world of indicators: The making of governmental knowledge through quantification. Cambridge: Cambridge University Press.

Stallabrass, J. (2007). What's in a face? Blankness and significance in contemporary art photography. October, 122, 71-90.

Verran, H. (2010). Number as an inventive frontier in knowing and working Australia's water resources. Anthropological Theory, 1o(1-2), 171-178. https://doi. org/10.1177/1463499610365383

Verran, H. (2015). Enumerated entities in public policy and governance. In: E. Davis \& P. J. Davis (Eds.), Mathematics, substance and surmise. (pp. 365-379). New York: Springer, Cham.

\section{About the author}

Jonathan Gray is Lecturer at the Department of Digital Humanities, King's College London; Cofounder of the Public Data Lab; and Research Associate at the Digital Methods Initiative (University of Amsterdam) and the médialab (Sciences Po, Paris). More about him can be found at jonathangray.org and he tweets at @jwyg. 